This is an electronic version of an article published in:

Early Years 27 (2), 131-144 (2008)

The journal is available online at:

http://www.informaworld.com/smpp/content $\sim \mathrm{db}=\mathrm{all} \sim$ content=a780631727 frm=titlel ink

Gardening with grandparents: an early engagement with the science curriculum

Mahera Ruby, Charmian Kenner, John Jessel, Eve Gregory and Tahera Arju

Department of Educational Studies

Goldsmiths, University of London

c.kenner@gold.ac.uk 


\title{
Gardening with grandparents: an early engagement with the science curriculum
}

\begin{abstract}
In many cultures, elders are revered within the extended family as a source of wisdom gained from long experience. In Western societies, this role has been marginalised by changes in family structure, and grandparents' significant contribution to children's upbringing often goes unacknowledged. A research study with families of 3-6 year olds in East London reveals how grandparents from a variety of cultural backgrounds passed on knowledge about growing fruit and vegetables to their grandchildren through joint gardening activities. Children learned to identify different plants, and to understand conditions and stages of plant growth. Grandparents from Bangladesh introduced children to a wide range of fruits and vegetables, and concepts were reinforced through bilingual communication. Analysis shows that these intergenerational learning encounters fostered children's scientific knowledge in ways that supported and extended curriculum work in the early years.
\end{abstract}

\section{Keywords}

grandparents, science, gardening, family learning, intergenerational learning, bilingualism

\section{Introduction}

This paper will first discuss how grandparents are playing an increasingly important role in childcare in the UK and internationally, yet their role as educators is rarely recognised in research or policy. Studies tend to focus on how parents prepare children for school learning, rather than examining interactions within the extended family. Home-school policies are also constructed around parental involvement. However, recent studies from a sociocultural viewpoint have highlighted the role of other family members as well as parents. The research project presented here breaks new ground by investigating intergenerational learning interactions between young children and their grandparents.

We will next describe how our study with families of 3-6 year olds in East London used questionnaires, interviews, videorecordings and scrapbooks to discover how grandparents from Bengali-speaking and English-speaking families were passing on 
skills, family history and cultural traditions to their grandchildren. Gardening emerged as an important activity for several of the families involved in the research, and this paper analyses aspects of children's learning as they helped grandparents grow fruit and vegetables.

By looking in depth at one particular videorecorded interaction, we show how fiveyear-old Sumayah was able to recognise a range of plants and was discovering the variety of conditions that foster plant growth. She could also identify stages of growth, using size and colour as salient characteristics. Her learning took place bilingually, using both Sylheti/Bengali and English. The context of growing fruit and vegetables as a joint enterprise with other family members, in order to contribute to the family's food supply, gave motivation and purpose to the development of Sumayah's gardening knowledge. When conducting the analysis, we draw on supporting data from scrapbooks, questionnaires and interviews with Sumayah's family and other children and grandparents involved in the research.

We then consider how our findings relate to programmes of study for early learning in science as specified by the National Curriculum in England. We demonstrate that the knowledge gained by these young children reinforces, complements and extends the learning taking place at school. In conclusion, we suggest that teachers need to be aware of children's home learning experiences in order to enable them to take full advantage of this valuable cultural knowledge base. 


\section{Grandparents as educators}

The importance of parental involvement in children's learning has been argued in a number of studies in the UK (Wolfendale and Topping, 1996; Desforges and Abouchaar, 2003) and the US (Padak et al, 2002). However, the contribution of grandparents is largely absent from such research, perhaps because they have been seen as playing a less significant role in the nuclear family consisting of parents and children living apart from other relatives, a structure more common in Western societies.

Cross-cultural studies based in a sociocultural approach tell a rather different story. Rogoff's research with Mayan families from Guatemala (1990, 2003) shows how children learn as 'apprentice' members of the wider community, involved in tasks that benefit the extended family as a social and economic unit. 'Guided participation' in learning (Rogoff, 1990) takes place through interaction with a variety of family members. The role of siblings as teachers, for example, is highlighted by Volk and de Acosta (2004) and Rashid and Gregory (1997; see also Gregory, 2001) in Puerto Rican families in a Midwestern American city and Bangladeshi families in London respectively. Research on grandparents' role in learning is a logical extension of this developing field.

Grandparents have a key part to play in passing on cultural knowledge to younger generations, especially in families that have migrated from their countries or communities of origin (Jessel et al, 2004). In studying the intergenerational learning encounter, we can make use of the concept of 'prolepsis' (Cole, 1996), the process by which knowledge is culturally re-shaped as it passes from one generation to another. 
Children's situated and authentic learning within the family group is a source of 'funds of knowledge' that can be tapped by schools, as shown by González, Moll and Amanti (2005). In their action research study, 'teacher ethnographers' in Arizona, USA, researched children's home and community learning and invited parents and other relatives into the classroom to demonstrate their skills in activities linked to the curriculum. Similar connections with family members as educators have been built in multilingual early years classrooms in London (Kenner, 2000), with Somali families in Canada (Masny and Ghahremani-Ghajar, 1999), and with Maori communities in New Zealand (Glynn and Berryman, 2003), all with beneficial results for children's learning. The approach of building links between home and school has been recommended to educational practitioners in a number of countries by, amongst others, Valdés (1996) and Zentella (2005) in the US, Whitehead (2004) in the UK, and Cairney (2002) in Australia.

Grandparents' particular contribution to 'funds of knowledge' is therefore an area of research with important implications for mainstream educators. This is especially so at a time when grandparents are increasingly undertaking childcare for working parents; for example, $46 \%$ of all family childcare in Britain is now done by grandparents (Lowe, 2000). Schools in the UK are currently beginning to broaden their home-school links to include work with grandparents (Gyllenspetz, 2006), and the research presented here offers conceptual support for this new area of early years practice. 


\section{Intergenerational learning in East London}

The project discussed in this paper is based in the field of cross-cultural research, drawing on sociocultural theory (Vygotsky, 1978) and taking an ethnographic approach to the study of home and community learning (Gregory, Long and Volk, 2004). We set out to investigate the intergenerational learning exchange between 3-6 year olds attending an East London primary school and their grandparents from different linguistic and cultural backgrounds. Our aims were to find out how intergenerational activities were co-constructed by the participants, and what kinds of knowledge were exchanged between the younger and older learners.

The study enabled us to explore a variety of aspects concerning intergenerational learning, including the relationships between grandparents and grandchildren that underpin the learning process (discussed elsewhere in Kenner et al, under review) and how an interlingual and intercultural exchange takes place within bilingual families (see Gregory et al, forthcoming). In this paper we focus on the value of home and intergenerational learning for young children, by examining the particular case of gardening as an activity through which scientific understandings can be developed, and discussing how such understandings relate to children's mainstream education.

\section{Methodology}

First we needed to gain information about the range of activities taking place in homes, and we therefore conducted a survey via a questionnaire delivered to all families at the school with children in the 3-6 year old age groups (Nursery, Reception and Year 1) who had regular contact with grandparents. 20 families answered this questionnaire, 17 of whom were from Bengali-speaking and 3 from English-speaking 
backgrounds, numbers that reflected the high proportion of British Bangladeshi children attending the school. Nineteen activities were asked about in the survey, ranging from playing, storytelling and taking children to the park to talking about family history, and families could add further categories of their own. Most grandparents engaged in 6-10 of these activities, showing the extent and variety of their support for children's learning. 'Gardening' was one of the categories we offered, and it was mentioned by eight grandparents from a variety of cultural backgrounds.

We then moved on to further data collection with nine focus families from the school, six of whom were British Bangladeshi, two that had English-speaking grandparents of white UK origin and one that included English-speaking grandparents from Guyana. Through interviews with grandparents and children and scrapbooks they made about the activities they did together, gardening again emerged as significant in several cases: the families of Sumayah, of Stephen, of Lizzie and her brother Sam, Oscar and his brother Cosmo, and Anayah.

We asked each family to choose an activity that children and grandparents particularly enjoyed, which we could then videorecord so that we could investigate aspects of the intergenerational learning encounter in more detail. Sumayah and her grandparents chose gardening, and we present below an analysis of the six-and-a-half-minute videorecording. First, the context of Sumayah's family life will be described. 


\section{Sumayah and her family at home}

Sumayah lives with her paternal grandparents, her parents, her baby sister, one of her aunts, her father's older brother, his wife and their two children, two teenage uncles, and one teenage first cousin ('cousin brother') whose mother died when he was a baby and who is looked after by the whole family. Sumayah (five years old and in Year 1 at school) and her other cousin brother (who is the same age and in the same class) are particularly close and call each other 'real' brothers and sisters. This extended family shares a house which they own on a fairly new housing estate in Tower Hamlets, backing onto a canal. The house is always busy and the front door is open most of the time with people coming in and out.

The family is very close-knit; the grandparents are the focal point and play an important role in all that goes on in the family. The grandmother is constantly busy, from showing her daughter-in-law how to bath a newborn baby to babysitting the grandchildren whilst their parents are occupied with work and household chores.

The scrapbook Sumayah made for the project represents the closeness of her relationship with her grandparents. The book is festooned with a large yellow satin bow on the cover. The first page shows a photo of Sumayah and her cousin brother sitting in front of their grandparents, dressed in beautiful clothes for the festival of Eid. Photos and artefacts, with comments by Sumayah, bring her British Bangladeshi family life into the scrapbook pages. A small bag of lentils is attached with the caption 'I help my dadi (her grandmother) with cooking dhal soup', whilst on the facing page is a bag of children's sweets and a Ferrero Rocher chocolate wrapper with the comment 'we bye (sic) lots of sweets and food to eat'. Sumayah and her cousin 
brother were accustomed to receiving such treats from their grandparents; when interviewed, Sumayah said 'They buy us presents: they call it 'surprise present'.'

One of Sumayah's first comments in her interview was 'I like to grow trees with Bubu and Dada (her grandmother and grandfather), like to go outside with both of them'. On several pages in her scrapbook, she chose to include leaves from the garden, reflecting the importance of gardening in her interactions with her grandparents. Her writing shows she can identify each leaf and indicates the participation of each family member in the gardening project: 'This is leaf from apple tree my dada (grandfather) made' and 'This is leaf from chilli tree my dadi (grandmother) made'. Sumayah also records the everyday work of looking after the garden area; one page consists of leaves with the comment 'Me and my couison (sic) brother help my dada and dadi clean the garden'.

\section{Learning with her grandmother in the garden}

In the videoextract, Sumayah and her cousin brother of the same age are working in the back garden with their grandmother. Two of our research team members, themselves Bengali-speaking, are with them, and Sumayah's mother is also present. The garden is relatively small and mostly paved. Maximum use is made of the soil area around the edges, with a great variety of fruit and vegetables growing there and in pots placed on the paving.

A number of events take place in the course of the extract. Sumayah first helps her grandmother collect up some vegetation which is lying on the paving. Sumayah offers to hold a carrier bag so that her grandmother, who is squatting on the ground, can put 
the leaves inside. Sumayah's mother suggests she should sweep the paving, which she begins to do with a broom, helped by her grandmother. Sumayah's cousin brother then arrives with a full watering can and the children take it in turns to water the fruit trees and several small plants in pots. The water runs out and Sumayah offers to refill the can. Meanwhile, the grandmother removes clothes from the washing line, putting them over her grandson's shoulder, and they take them inside. When Sumayah returns with the watering can, she and her cousin do the watering with their grandmother, each placing their hands close together to hold the can. During the activity, Sumayah talks with her grandmother and cousin about what they are doing, responds to questions from her mother about the trees and plants and makes her own comments.

The following analysis highlights several aspects of Sumayah's understanding demonstrated in the data, each of which will be discussed in turn: identification of plants, conditions that facilitate growth, stages of plant growth, size and colour as salient characteristics of growth, and a sense of ownership and mutual care for the plants and the garden. Throughout the episode, we see how this understanding is shaped by joint activity between Sumayah and her cousin with the support of their grandmother, who skilfully promotes a collaborative learning environment.

Where quotes are used in the analysis, English is in plain font and Bengali (translated) is in italics. This draws attention to the ways in which both languages are used for learning. 


\section{Identifying plants}

In this relatively brief period of activity, Sumayah identifies a number of plants and trees. When her mother asks her about a particular tree, 'what tree is that?', she names it correctly as 'apple tree'. At another moment, Sumayah mentions a 'pumpkin tree' (ie pumpkin plant) in Bengali, and when her mother asks in Bengali for her to be more specific ('what tree is that?'), she responds by giving the type of pumpkin, 'khodu'. Later her mother mentions 'tomato tree' and 'lemon tree' and asks Sumayah to fetch the 'lemon tree your dada growed'. Sumayah brings the correct plant and states confidently 'this is the lemon tree that dada growed'. Next her mother asks her to 'show the apple tree that dada growed' and Sumayah does so and identifies a second apple tree too. Finally she names a 'tomato tree' and when her mother asks about another plant 'what trees are they', Sumayah replies in Bengali 'potato trees'.

Added to Sumayah's naming of chilli tree leaves in her scrapbook, these comments show she can distinguish between several different kinds of plants and trees according to criteria such as leaf shape. Learning of plant names happens as part of the gardening activities - for example, when Sumayah's mother tells her to 'go and water the pear tree', and the knowledge is reinforced by talk in both English and Bengali. A number of herbs are also grown in the garden and are familiar to Sumayah, though not mentioned in this particular episode.

Through learning with her grandparents, Sumayah realises the difference between useful plants and weeds. When her grandmother is gathering vegetation from the paved area and putting it into a plastic bag, Sumayah recognises some of the leaves and is concerned that they should not be thrown away, pointing to the area of soil just 
alongside and saying 'when you put that...' (meaning that this is a plant that could usefully be grown). Her grandmother reassures her 'I'll sort them, put that aside inside', meaning that she will take the bag into the house and salvage the useful plants.

\section{Understanding conditions of growth}

Both Sumayah and her cousin understand the importance of watering the plants, and compete to undertake the task. When her cousin appears holding the watering can, Sumayah immediately says 'I have to do the water...on my trees', and he replies with 'I want to give it'. Her mother reinforces the need to water by saying 'give it to your little ones' (ie to the plants the children are growing in pots). Later Sumayah states that the pumpkin tree needs watering: 'put the water in the pumpkin tree, I want to'. The two children and their grandmother comment on the need for more water when the can runs out: Sumayah's cousin says 'the water is finished', his grandmother confirms 'yes it's finished', and Sumayah offers to fetch more by saying 'do you want $<m e>$ to get some more?' As grandmother and grandchildren engage in joint watering, Sumayah's mother reinforces the link between water and plant growth by saying 'tell 'em to grow - tomorrow!'

The children are also learning about the amount of water needed by each plant or tree. The joint watering activity where the children hold onto the can with their grandmother gives them a physical sense of the angle at which to position the spout and how much water to pour on each plant. When Sumayah's grandmother instructs them to water a new area ('OK give it here now'), Sumayah points out that the water has run out again ('there's no more') and her grandmother reassures her that the need 
is not urgent ('OK don't need any more'). There is discussion about over-watering when Sumayah directs her cousin to water another patch ('give there') and he contests her opinion, saying 'it's too much'. Sumayah's mother also questions her daughter's directive, asking 'didn't you water that once?' and suggests the children should water a different area instead: 'it's too much there, give it here'. Sumayah then asks in Bengali if they should water the 'potato trees', and her grandmother explains it is not necessary: 'yesterday we did it', showing that some plants need less water than others.

\section{Finding out about stages of plant growth}

Sumayah shows her interest in monitoring the growth of different plants in the garden. She talks about how the khodu pumpkin plants will grow, switching between Bengali and English in her comments: 'khodu grow won't but it's a little bit tiny - it's going to large one'. There are two seedlings in the pot her grandmother is attending to, one of which is smaller than the other and Sumayah seems to think one is growing well but the other one is not. Her mother asks 'is it growing?' and Sumayah replies 'yes...but little one isn't'. She points out to her grandmother that there are new leaves growing at the tip of the lemon tree: 'bubu, that what you can see these marks, they're new'. She knows that seedlings and young plants are sometimes kept indoors, since she says of the lemon tree in its pot 'put this in my house'. She also knows that seeds, if cared for, will eventually emerge as plants after a period of time; whilst watering a patch of ground where nothing can yet be seen she comments 'these are gonna grow'.

\section{Knowing how colour and size change with growth}

Sumayah demonstrates her understanding of how to recognise tiny new leaves in her comments above on the lemon tree seedling, and shows her knowledge of how large a 
particular plant is likely to grow through her discussion of the khodu pumpkin. She also knows colour is a salient characteristic for monitoring plant growth. Whilst pointing to apples on one of the trees, she recognises colour changes in fruit caused by ripening, saying 'This is a apple tree growing a little bit red, there's one and these are growing lots of...red apples....the colour, some of them are green'.

\section{Caring for the garden and feeling a sense of ownership}

Sumayah is keen to help her grandmother look after the garden area. When her grandmother is collecting up leaves and putting them into a plastic carrier bag, Sumayah offers to hold the bag, saying 'give it <to me $>$ '. Her grandmother does so and asks her grand-daughter to 'hold it up' so that she can easily scoop in the vegetation. Next Sumayah's mother instructs her to 'get the broom out' and Sumayah energetically sweeps the paving. Her grandmother's hand hovers behind Sumayah's during the sweeping, ready to catch the broom handle if she should let go. Then her grandmother takes the broom and shows Sumayah how best to sweep, after which she leaves Sumayah in charge.

The garden is the collective responsibility of the family, with each plant and tree being cared for by a particular family member. Sumayah's cousin brother points out three little pots where seedlings are growing and comments 'this one is auntie's, this one sister's and this one uncle's'. Sumayah's mother refers to 'lemon tree your dada growed' and 'the apple tree that dada growed', and her grandmother reminds her to take care of plants grown by others: 'don't tear it then' (of the lemon tree seedling) and 'look out, you're going to break my plants' (when Sumayah drops the broom on the ground). Sumayah's own comments in her scrapbook show the recognition of the 
work put in by each family member to grow a tree: 'the apple tree that dada growed' and 'the chilli tree that dadi growed'.

The children have their own plants to care for; Sumayah's mother refers to 'your pots' and encourages them to water 'your little ones'. Sumayah feels a collective sense of ownership with other family members - at one point she starts to say 'this is our....' and also her responsibility as an individual gardener, shown when she comments 'I have to do the water...on my trees'.

The children's contribution to the garden is fully recognised by the family along with that of the adults. Through interviewing Sumayah's grandmother, we discovered that the children were left in charge of the garden when the grandparents went to Bangladesh, and that Sumayah had decided that a consignment of apples should be sent to Bangladesh because they were 'grandfather's apples'.

\section{A collaborative learning environment}

During this episode, we see how Sumayah's grandmother mediates between the two children, encouraging them to act jointly as gardeners and maintaining their focus on the task in hand. When Sumayah's cousin brother arrives with the watering can, Sumayah wants to water first and tries to grab the can, but their grandmother indicates that he should start. Sumayah is temporarily annoyed but her grandmother soon lets her have a turn. Her cousin then objects, saying 'dada I want to give it', and his grandmother reassures him 'you'll give it'. After a short while he starts to insist 'I want to give it', and she uses a pet name to emphasise that he will soon have his turn 'oh dear, dear, you'll give it, you'll give it now'. She then negotiates with Sumayah 
for the handover of the can 'OK now give it to your brother, you give it now', and Sumayah does so.

Building on their grandmother's example, the children co-construct an approach of negotiation with her. When she is passing washing from the line to her grandson, she asks him if he would like to take an item off the line ('do you want to take it?') and he offers to carry an item she already has in her hand ('do you want to give that one?'). Sumayah offers to refill the watering can by saying 'do you want $<$ me $>$ to get some more?' Finally, when both children want to water and their grandmother is holding the can, she allows them to each hold the handle with her and swing the can to and fro as a joint activity. Sumayah's mother reinforces this mutual action by saying 'everyone hold onto that and tell 'em to grow - tomorrow!'

\section{Gardening by families from different cultural backgrounds}

Gardening emerged as an important activity in two of the other focus families involved in the project. Stephen, aged six, grew plants with his grandmother Gloria (who came from Guyana) in pots and windowboxes on the balcony of her flat in East London. Lizzie and Sam helped their grandmother Hazel (from the UK) in her large garden in the countryside south of London. In these different settings and with grandparents of different cultural backgrounds, we found a similar sense of shared enjoyment and learning.

Gloria promoted a sense of ownership for Stephen with regard to the plants they grew together, telling him they were his and he needed to look after them. By watering the plants whenever he visited his grandmother, Stephen saw how this contributed to 
plant growth over a period of time. Gloria also grew tomatoes with Stephen in order to persuade him to eat a fruit he did not originally like, a strategy that worked when Stephen could not resist the delicious results of his own work as a gardener.

In the scrapbook made by Hazel about activities shared with grandchildren Lizzie and Sam, she includes photos of them working in the garden to grow vegetables and flowers. Their knowledge of different kinds of plants was supported by doing observational drawings, for example of blossom picked in the garden. They found other items of interest from the natural world there too, such as a butterfly chrysalis or bird's egg, and a moth that Lizzie and her grandmother identified by looking up information in a nature book and on the internet.

The grandmother of Oscar and Cosmo, Pam, talked of the children's delight in digging in the garden and getting muddy, and Anayah's grandmother also mentioned gardening with her grand-daughter. We therefore know that gardening was a shared activity between children and grandparents in five of the nine focus families, suggesting that it is a significant resource for intergenerational learning.

\section{Relevance to the science curriculum}

Here we comment on how Sumayah's home learning relates to the National Curriculum for primary schools in England (DfES, 2004). Whilst science curricula in other countries may vary in specific content, there is likely to be an overlap in core concepts. For example, teachers in England are required to 'promote pupils' spiritual, moral, social and cultural development through science' (DfES, 2004: 8). Spiritual development should be facilitated through 'pupils sensing the natural, material and 
physical world they live in, reflecting on their part in it, and exploring questions such as when does life start and where does life come from?' (ibid: 8). The above episode demonstrates how Sumayah experiences a close relationship to the natural world through the senses of touch and sight as she handles seeds, plants them in the earth, waters them and weeds around them, and watches the tiny freshly-coloured leaves and fruits emerge. She is aware of the part she plays in the care of the garden, and thus in the growth and development of the plants within it, as a member of a household spanning three generations for whom this is an important shared task. Her grandparents provide a learning environment in which Sumayah can explore and ask questions about how life starts, and she knows that her seeds will grow into seedlings and eventually into plants and even trees.

With regard to moral development, Sumayah has a sense of responsibility as well as accountability for producing fruit and vegetables to contribute to the family diet. She is very protective of the plants she is growing and wants to water them herself, notices when she thinks that useful plants are being thrown away amongst the weeds, helps to take overall care of the garden area and makes an effort to send the fruits of her grandparents' hard work to them when they are away in Bangladesh.

Through gardening, Sumayah gains a wealth of social and cultural knowledge about the foods that are eaten in her family home. Some are typical of Bangladesh, but the little garden also represents 'fusion' gardening for Sumayah, since a shared culture is being constructed through the vegetables, fruit and herbs that are grown there. Alongside 'khodu' (pumpkin), 'lai phata' (mustard) and 'dhanya' (coriander), she is learning how to grow apple and pear trees that are not found in Bangladesh. Her 
grandparents have adapted their considerable experience of growing plants and trees to the climate and soil conditions encountered in a London garden, and are passing on this knowledge to their grandchildren.

Another aspect of the National Curriculum is 'promoting key skills through science' (DfES, 2004: 8). One of these is 'communication', and Sumayah demonstrates this when she names plants and describes their colours in dialogue with other family members. As part of this interaction, she also makes spontaneous remarks on what new leaves look like and predictions of what will happen to some of the plants in the garden (that one of the 'khodu' pumpkin seedlings will not grow very big and that green apples will turn red).

By participating in a team with her grandparents and other family members to grow plants in the garden, Sumayah is 'working with others through carrying out scientific investigations' (DfES, 2004: 8). The team collectively cares for the plants, taking over if one person is ill or away, and members observe each other's plants as well as their own to find out what conditions best foster each plant's development.

Sumayah is involved in 'improving own learning and performance' (DfES, 2004: 8) by predicting what will happen to particular plants and then finding out whether her predictions are borne out in practice. She has the opportunity to improve her skills from year to year depending on whether plants thrive or fail. 
The National Curriculum specifies particular aspects of scientific knowledge to be gained in Key Stage 1 (for five to seven year olds). For example, under the heading of 'green plants' (DfES, 2004: 17), it specifies that pupils should be taught:

a. to recognise that plants need light and water to grow

b. to recognise and name the leaf, flower, stem and root of flowering plants

c. that seeds grow into flowering plants

To find out in the classroom that light and water are needed for plants to grow, pupils usually conduct the classic experiment of growing cress on blotting paper and depriving some seeds of light and others of water, whilst giving other seeds both. This leads to discussion about why some grow whilst others do not. Sumayah's experience in the garden further supports her understanding of the need for light and water, by providing examples of how different quantities are required for different kinds of plant. She knows whereabouts in the garden each plant is placed in order to receive the right amount of sun, and also that not all plants are watered every day. She observes plants growing from seeds into seedlings with roots, stems and leaves.

Under the heading of 'living things in their environment' (DfES, 2004: 17), the curriculum requires that pupils should be taught to 'find out about different kinds of plants and animals in the local environment' and 'care for the environment'. Sumayah is very aware of the different types of plants growing in their garden in terms of Asian vegetables, trees and herbs as well as more typical English ones. She is also an 'apprentice' gardener with her grandmother being the 'expert' who shows her through 'modelling' how to take responsibility for the environment around her. 


\section{Conclusion}

Our research with Sumayah's family highlights the construction of different frameworks of learning around scientific experience at home and at school. At home, each of Sumayah's gardening experiences is framed within the context of an ongoing activity process designed to achieve a shared goal. In comparison, school experience tends to be framed in the context of a defined, time-limited task designed primarily to achieve individual learning. However, we would suggest these frameworks of learning are complementary rather than competing ways of building knowledge.

Through working in the garden with her grandparents, Sumayah engages in a longitudinal study of how elements such as sunlight, watering and soil type contribute to the development of plants and trees. In addition, she witnesses at first hand the effect of actual outdoor conditions such as weather variation. This experience of the 'bigger picture' with regard to plant growth, looking at how key factors interact, extends the experience gained in the classroom through activities such as depriving seedlings of the elements of light and water in turn. The 'bigger picture' also contributes to a perception of science as a continuing narrative with scope for further exploration, whereas in the classroom the story can have a more defined beginning and end.

Sumayah's shared goal of growing fruit and vegetables with her grandparents to contribute to the family's food supply provides a strong intrinsic motivation (Gardner, 1985) for investigating the world of plant growth. This complements the largely extrinsic motivation that school offers through the reward of individual achievement. Both types of motivation are necessary for future success, since workplaces require 
not only well-qualified individuals but also teamwork between people of different generations with different kinds of experience. Sumayah already appreciates the importance of intergenerational teamwork in her family's garden, where each person makes a particular contribution building on that of others, or compensates when another person is absent.

Our analysis links with that of Moll et al (1992) on ways in which Mexican American families contribute to their children's learning through 'flexible, adaptive, and active' social networks for household activity. Moll and his co-researchers point out that the labour histories of families result in 'historically accumulated and culturally developed bodies of knowledge and skills essential for household or individual functioning and well-being' (Moll et al, 1992: 133) which they define as 'funds of knowledge'. Similarly, Azmitia et al (1994: 22) found that children's participation in household chores in low-income families in California 'appeared to foster responsibility, selfmanagement, understanding of family relationships and obligations, and the development of metacognitive skills such as planning and organising tasks, and monitoring and evaluating outcomes'.

Our data reveal that grandparents make a particular contribution to 'funds of knowledge'. Referring back to the concept of 'prolepsis' (Cole, 1996), we see that the experience of Sumayah's grandparents is transmitted to her and continues to be held within the family, but re-shaped as it is constructed together with the grandchild generation in a new cultural context, such as growing plants from Bangladesh under British weather conditions. Our research also demonstrates how 'funds of knowledge' are built through the creative combination of two languages, with Sumayah and her 
cousin using Bengali to construct ideas with their grandparents, whilst simultaneously thinking through those ideas in English, the language of school. This process is reminiscent of the code-switching observed by Drury (2004) as young Paharispeaking siblings in Hertfordshire, UK, learned from each other at home. The additional dimension provided by learning with grandparents is that, whilst sibling talk tends to switch increasingly into English as children go through primary school (Murshad, 2002), the older generation retains Bengali as an important ongoing resource for grandchildren's linguistic development.

Having established the existence of 'funds of knowledge', Moll et al (1992) argue for the development of 'ethnographically informed classroom practices' in which teachers invite families to participate in children's school learning. The combination of Sumayah's knowledge and skills from home and school has considerable potential, which will be maximised if her teachers are aware of her home learning and make efforts to 'translate' between her different experiences. For example, a school could dedicate a small patch of ground to 'gardening with grandparents', so that elders can share their experiential knowledge with children. Also, school science requires the systematic activity of recording observations, often written down in tabular form. Sumayah and her grandparents are more likely to keep a mental record of their own systematised practice (such as watering a particular plant every other day), and the ideas arising from this approach can be drawn upon in classroom discussion.

Sumayah herself is ready to play her part in this development of home-school practice. She is already familiar with the need to combine different kinds of knowledge, not only from home and school, but also from Britain and Bangladesh. 
This melding of different kinds of experience to produce completely new knowledge has been called 'syncretism' by Gregory et al (2004), and Sumayah is helping to create new understandings in more than one language around the growth and development of plants. Finally, the garden is a demonstration to Sumayah that the dual aspects of her British Bangladeshi identity can co-exist in harmony, thus contributing to the strong sense of self that she manifests through linking home and school culture.

\section{Acknowledgements}

Our thanks go to the families who participated in the research project, and to Hermitage Primary School.

This research was funded by the ESRC (Award R000220131).

\section{References}

Azmitia, M., Cooper, C., Garcia, E., Ittel, A., Johanson, B., Lopez, E., Martinez-

Chavez, R. and Rivera, L. (1994) Links between home and school among low-income Mexican-American and European-American families. Washington, DC: National Center for Research on Cultural Diversity and Second Language Learning.

Cairney, T. (2002) Bridging home and school literacy: in search of transformative approaches to curriculum. Early Child Development and Care 172 (2), 153-172. Cole, M. (1996) Cultural psychology: a once and future discipline. Cambridge, Mass.: Harvard U.P.

Department for Education and Skills (DfES) (2004) The National Curriculum for England: Science, Key Stages 1-4. Annesley, Notts: DfES. 
Desforges, C. and Abouchaar, A. (2003) The impact of parental involvement, parental support and family education on pupil achievement and adjustment. London: DfES.

Drury, R. (2004) Samia and Sadaqat play school: early bilingual literacy at home. In Gregory, E., Long, S. and Volk, D. (eds) Many Pathways to Literacy: Young Children Learning with Siblings, Grandparents, Peers and Communities. London:

RoutledgeFalmer.

Gardner, R. (1985) Social psychology and second language learning. London: Arnold.

Glynn, T. and Berryman, M. (2003) A community elder's role in improving reading and writing for Māori students. In Barnard, R. and Glynn, T. (eds) Bilingual children's language and literacy development. Clevedon: Multilingual Matters. González, N., Moll, L. and Amanti, C. (2005) Funds of knowledge: theorizing practices in households, communities and classrooms. Mahwah, New Jersey: Erlbaum.

Gregory, E. (2001) Sisters and brothers as language and literacy teachers: synergy between siblings playing and working together. Journal of Early Childhood Literacy $1(3), 301-22$.

Gregory, E., Long, S. and Volk, D. (eds) (2004) Many Pathways to Literacy: Young Children Learning with Siblings, Grandparents, Peers and Communities. London: RoutledgeFalmer.

Gregory, E., Arju, T., Jessel, J., Kenner, C. and Ruby, M. (forthcoming) Snow White in different guises: interlingual and intercultural exchanges between grandparents and young children at home in East London. Journal of Early Childhood Literacy. 
Gyllenspetz, I. (2006) Learning with grandparents: grandparents and schools working together to support basic skills development. London: The Basic Skills Agency.

Jessel, J., Gregory, E., Arju, T., Kenner, C. and Ruby, M. (2004) Children and their grandparents at home: a mutually supportive context for learning and linguistic development. English Quarterly 36 (4), 16-23.

Kenner, C. (2000) Home pages: literacy links for bilingual children. Stoke-on-Trent: Trentham Books.

Kenner, C., Ruby, M., Gregory, E., Jessel, J. and Arju, T. (under review)

Intergenerational learning between children and grandparents in East London. Journal of Early Childhood Research.

Lowe, S. (2000) Grandparents: here we go again. The Guardian G2, 14/12/2000: 8. Masny, D. and Ghahremani-Ghajar, S. (1999) Weaving multiple literacies: Somali children and their teachers in the context of school culture. Language, Culture and Curriculum 12 (1), 72-93.

Moll, L., Amanti, C., Neff, D. and González, N. (1992) Funds of knowledge for teaching; using a qualitative approach to connect homes and classrooms. Theory into Practice 31 (2), 132-141.

Murshad, A. (2002) Tools for talking. Reading, Literacy and Language 36 (3), 106112.

Padak, N., Sapin, C. and Baycich, D. (2002) A decade of family literacy: programs, outcomes, and future prospects. Information Series no. 389. Columbus, Ohio: ERIC Clearinghouse on Adult, Career, and Vocational Education, Ohio State University. Rashid, N. and Gregory, E. (1997) Learning to read, reading to learn: the importance of siblings in the language development of young bilingual children. In Gregory, E. 
(ed) One Child, Many Worlds: Early Learning in Multicultural Communities.

London: David Fulton.

Rogoff, B. (1990) Apprenticeship in thinking. New York: Oxford University Press.

Rogoff, B. (2003) The cultural nature of human development. New York: Oxford University Press.

Valdés, G. (1996) Con respeto: bridging the distance between culturally diverse families and schools. New York: Teachers College Press.

Volk, D. with de Acosta, M. (2004) Mediating networks for literacy learning: the role of Puerto Rican siblings. In Gregory, E., Long, S. and Volk, D. (eds) Many Pathways to Literacy: Young Children Learning with Siblings, Grandparents, Peers and Communities. London: RoutledgeFalmer.

Vygotsky, L. (1978) Mind in society. Cambridge, Mass: Harvard U.P.

Whitehead, M. (2004) Language and literacy in the early years ( $3^{\text {rd }}$ edition). London: Sage.

Wolfendale, S. and Topping, K. (1996) Family involvement in literacy. London: Cassell.

Zentella, A. (ed) (2005) Building on strength: language and literacy in Latino families and communities. New York: Teachers College Press. 